\title{
Greek orthodoxy
}

\section{The first of two articles commenting on the research policy and universities of Greece by $\mathbf{E} \mathbf{M}$ Pantelouris describes the patriarchal and bureaucratic structure of Greece's higher education system.}

WHY, one may ask, do 30,000 Greek
students, representing nearly $30 \%$ of the student community of Greece, study abroad? Is this a vote against Greek higher education? Or are there just too few places for too many students? To describe the system is an answer in itself, and 1 shall attempt to do that here.

The aspiring Greek student cannot rely on the education provided by his or her six years of secondary schooling to secure a university place. Entrance is by written examination, conducted uniformly throughout the country, and to prepare effectively for these examinations, secondary school pupils commonly attend classes run by private cramming schools, which are a growth industry in Greece. Quite often, a young man or girl will spend a whole year after coming out of secondary school attending these 'frontisteria' before attempting, or re-attempting, the university entrance examination. Pressure is high, as the 1977 figures illustrate: slightly over 13,000 places were available for some 78,000 applicants (see Table 1).

This first hurdle over, the successful candidate embarks on a degree course that lasts as a rule four years (more for medicine and for some branches of engineering). Degrees are rather general, with six or more subjects continued to the fourth year. Lectures are formal and ex-cathedra, a format aggravated by the relative absence of a large body of published books in science subjects, and the extremely poor library facilities. Textbooks prepared by the professor in charge of each course are produced and distributed free by the government. This is very helpful, as few textbooks can be published economically in Greek, but might fossilise lecture courses.

There is nothing comparable to the British 10:1 student-staff ratio. No average figure can be given, but however calculated, the ratio would be several times higher. The professor of a 'chair' is the only one officially entitled to lecture to students, except for one or two 'authorised' sub-professors (ifigitis). The rest of the staff are kept incommunicado, except for the laboratory sessions. It has been put to me that they are selected as demonstrators rather than lecturers: most of them still have no higher qualification than a primary degree. Teaching is thus concentrated in the hands of the professor.

$\overline{D r}$ E. M. Pantelouris visited Greece as a Nature travelling fellow.
Table 1 Entrants by examination to university level institutions $\uparrow, 1977-78$

\begin{tabular}{|c|c|c|c|}
\hline $\begin{array}{l}\text { Law* } \\
\text { Economics* }\end{array}$ & $\left.\begin{array}{l}2,896 \\
3,140\end{array}\right]$ & total & 6,036 \\
\hline Literature, philosophy & 1,145 & & \\
\hline $\begin{array}{l}\text { Theology } \\
\text { Modern Languages }\end{array}$ & $\begin{array}{l}100 \\
785\end{array}$ & total & 2,030 \\
\hline $\begin{array}{l}\text { Scientific and } \\
\text { agricultural }\end{array}$ & & & 4,329 \\
\hline $\begin{array}{l}\text { Medicine, pharmacy, } \\
\text { veterinary science }\end{array}$ & & total & $\begin{array}{r}1,017 \\
13,412\end{array}$ \\
\hline
\end{tabular}

*About a third of law and economics students are gainfully employed and hence in effect part-timers. For comparison, in the UK about $30 \%(212,000$ including 49,000 of the Open University) of students -including postgraduates-are part-time $\dagger$ Excluding physical education, teacher training and military schools

Table 2 An estimate of the number of Greek students abroad (before 1976)

Student population in Greece at university level

Total of Greek students abroad* 80,000

Annual student entry at universities abroad

Distribution of Greek students abroad: $\begin{array}{lllll}\text { Italy } & \ldots & \ldots & \ldots & 55 \%\end{array}$ UK France $\cdots$ Germany USA

Others

$\cdots$

$\cdots$

$\cdots$

$\ldots$
$\ldots$
$\ldots$
$\ldots$

* Based on applications in 1975 for foreign exchange for the purpose of financing fulltime studies abroad

\section{Academics and bureaucracy}

Academic staff are also utterly dependent on the professor for tenure. Appointment to an assistantship lapses after nine years, unless a doctorate is obtained-an invitation to professors to grant internal doctorates to some to save them from redundancy. After a further six years, it becomes necessary to submit another thesis for the title of hyphigitis (or 'dozent'), some of whom may eventually be entrusted with a course or part of a course. Laboratory facilities, and acceptance of theses for such in-service internal degrees, depend in practice on the discretion of the professor, and reflect more his decisions about continuation of employment rather than any independent assessment of research ability.

Unavoidably this archaic system lowers the level of undergraduate teaching and prevents intellectual communication between staff and student. The students' response is disenchantment with the system, and the short term attitude that one is there just to get a degree of sorts, as nothing else can be got-unless it is the intensive politicisation reflected in the slogans that completely deface the walls of university buildings.

Of course, students and staff are aware of the shortcomings of the system, care about it, and agitate. And it must be stressed that this system is breached by commonsense in many departments, where younger professors begin to bring to bear the approach under which they themselves trained abroad in the Anglo-Saxon world or elsewhere. But there remains in all cases the stranglehold of the greatest scourge of Greece : bureaucracy. If a professor wishes to authorise his second-in-command to give a course of lectures, the move has to be approved by somebody 'at the ministry', who will first calculate whether the lecturing load of the professor entitles him to such help-because an honorarium will be paid. Similarly, after an annual grant has been allocated, the department still has to submit for approval a list of purchases before they can be effected; so that work can be delayed for months because a chemical cannot be purchased outright. I have come across cases where the professor pays from his pocket to save the situation.

Here we come to the real key obstacle to reform: the tradition by which university regulations are nearly uniform for all institutions, and acquire their force through the ministry and publication in the government Gazette; that is through a centralised extra-university and political organ. University independence is restricted; and in abnormal periods-of which fortunately the present is not oneprofessors are dismissed or appointed by the will of the minister.

Yet paradoxically, the key to improvement lies with the government. If matters were left to the ability of universities to renew themselves, the impression is that the older Athens institutions would remain static, although the outcome could be different at the newer University of Thessaloniki. In one institution with some 25 professors I was told that only a handful favour reforms. To understand these attitudes it has to be taken into account that the most influential groups of professors are those in fields such as medicine and engineering, where titles of professor, hyphigitis, and so on are springboards for lucrative private practices, consultancies, and membership of innumerable committees. 

'chair' system with a so-called sector system. Students and staff understand this to mean independence of university teachers in matters of lecturing and marking in their speciality, choosing their own research and participating in the running of academic affairs. The long incubation of the law, however, is giving rise to suspicions that the sectors will emerge as nothing more than groupings of related chairs as before.

It is to be hoped that the government may in the end come down on the side of actual, not simply cosmetic, changes that might enable Greek universities to gradually become something beyond mass producers of graduates, and rise to be schools for researchers. This they are definitely not at present.

For example, facilities cannot be expanded speedily, under the current pressure for places, to achieve overall a better staff-student ratio and to make possible the general adoption of more useful working methods. It should however be feasible for science faculties to introduce research-oriented streams for their third and fourth year students. Entry into these streams would be by merit as judged by the student's performance in the first two years, and the numbers accepted could increase as more facilities become available. In this stream, subjects would be dealt with in depth, and tutorials, dissertations and research projects would replace set practicals and lectures.

Academic staff should be given a
A law is promised to replace the

greater role, not indiscriminately, but in recognition of higher qualifications obtained outside the employing department, that is, under present circumstances, in reputable centres abroad. Leave of absence for the purpose should be available.

Furthermore, non-professorial staff should be free, indeed encouraged, to seek, individually or in groups, research grants and thus to participate in government plans to stimulate problemoriented research.

What has been said is sufficient to explain the annual migration of aspiring students. As undergraduates, they seek a place that was denied them at home. Naturally, most go where entry to a university is - or rather was - an uncomplicated and undemanding business. Thus more than half of them jump from the frying pan of the Greek into the fire of the Italian system. Even Romania has been recently invaded, and is now, like Italy, taking steps to reduce numbers (Table 2 ).

As far as postgraduate studies are concerned, it would be an excellent thing if Greeks went abroad so as to keep, on their return, national research within the mainstream of world science. In practice, the potential benefit to the country-and to themselves -is reduced by the haphazard acceptance of places anywhere, without due regard to the subject of the research degree, and the suitability of accepting institutions. However, despite its wasteful and unfair character, the process is creating a large pool of people trained in a variety of spheres. It is another matter whether Greece can

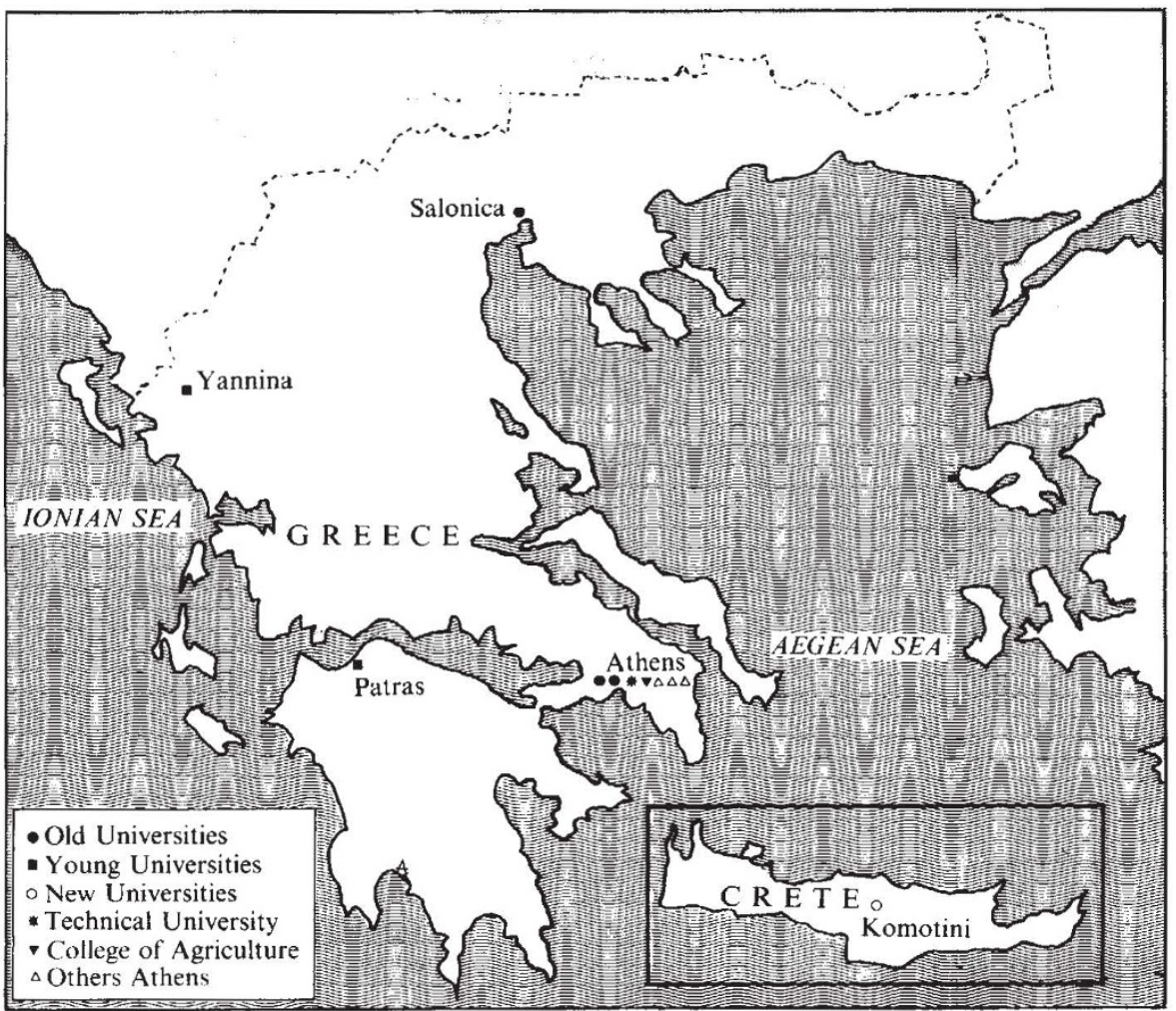

make rational use of them.

\section{Reforms}

Against this background, the determination of the former and the present governments of $\mathrm{Mr} \mathrm{K}$. Karamanlis to reform the educational system becomes better understood.

Compulsory school attendance is being extended from six to nine years, the first six in a primary school and the other three in a junior secondary. In this junior secondary, classics will be studied in modern Greek, thus allowing a shift of emphasis from grammar to content, and making an important saving of time for modern subjects.

After completion of the junior secondary course, young people will sit examinations for entry to a senior secondary school of either an academic, or a technical-vocational stream. On emerging from the academic secondary, people will be entitled to a university place without entrance examinations (this will take effect as from 1980). Pupils who fail to gain entrance to either type of senior secondary will be enlisted for shorter vocational courses.

Putting such changes into speedy effect is no mean task. Change is proceeding apace, and is accompanied by the appointment of new teachers and the building of new schools at the rate of 1,500 classrooms per year. The demotic form of modern Greek has in the meantime been introduced throughout the educational system. New and better schoolbooks have been produced in record time. Investment of some $\$ 250$ million in technical education has just been announced by the government.

At the level of higher education, the young universities of Patras and Yannina are expanding steadily, and two new institutions are being established in Thrace and in Crete. There should, eventually, be sufficient places within the country for most qualified finalists of the senior secondary schools.

Some serious criticism can be made of the way in which the new universities are being set up. Under local pressure, the various faculties of the University of Crete will be scattered throughout the island, making impossible the creation of a coherent campus.

It is also unfortunate that planning of the new universities has been entrusted to detachments of professors from the old institutions. Although some of these people are very distinguished, the risk remains that the new establishments too will be made in the Bavarian style of the old ones. A unique opportunity of introducing creative diversification and innovation into the system will have been missed. Is it too late? 